\title{
An Improved GM(1,1) Model of Marketization of Forest Ecological Compensation based on Health-Cultivation Industry
}

\author{
Xingang Wang ${ }^{1}$, Shide $\mathrm{Ou}^{2}$, Shangzhi Yue ${ }^{3 *}$ \\ ${ }^{1}$ School of Business, Yulin Normal University, Yulin537000, China \\ ${ }^{2}$ School of Mathematics and Statistics, Yulin Normal University, Yulin537000, China \\ ${ }^{3}$ College of Economy and Management, Northeast Forestry University, Harbin154000, China
}

Received: June 23, 2021. Revised: December 11, 2021. Accepted: January 10, 2022. Published: January 12, 2022.

\begin{abstract}
In the context of supply-side structual reform, the marketization of forest ecological compensation is an inevitable requirement under the market economy. The forest health-cultivation industry, which explores the new method to utilize the forestry resources, is a new direction of forestry firms and is the production of supply-side structural reform. From the perspective of forest health-cultivation industry, this essay explores the possibility of the marketization of forest ecological compensation based on forest health-cultivation industry, and predicts the willingness of people to pay for the ecological service by using the original number of tourists in forestry tourism and leisure industry tourism between 2010 and 2015 and adopting the improved GM $(1,1)$ model. The result shows that people's willingness is increasing. It is predicted that, by 2023 , the number of tourists in forestry tourism and leisure industry tourism will reach 8.98 billion. The development of forest health-cultivation industry has introduced the market mechanism for forestry development, which makes up for the deficiency of the existing compensation mechanism characterized by low compensation standards and single channel of funding. The increase of people's demand for ecological tourism and the boom of forest health-cultivation industry which provide a new opportunity for the marketization and diversification of forest ecological compensation mechanism.
\end{abstract}

Keywords-Supply-side reform, forest health-cultivation industry, forest ecological compensation marketization, improved GM $(1,1)$ model, demand for forest ecology

\section{INTRODUCTION}

$\mathrm{B}$ EING the most important link of the earth's carbon-oxygen balance, forest plays an important role in nitrogen fixation and oxygen production, wind prevention and sand fixation, and conservation of soil and water[1]. However, with the development of industry, forest protection faces a great challenge. An effective way to resolve the prominent contradiction between forest ecological value and economic value is to ecologically compensate the forest[2]. Compared with the government-oriented ecological compensation, which is characterized by comparative splitting of compensation subjects, single channel of funding, and low compensation standards, a new market-oriented and diversified ecological compensation mechanism can make up for the deficiency of the existing mechanism[3-4]. The target of "establishing the mechanism of market-oriented and diversified ecological compensation mechanism "was clearly stated in the report of the 19th National Congress of the CPC. The improved gray model $\mathrm{G}(1,1)$ is used in the paper to predict the number of people in the next eight years based on the number of people in the forest tourism and leisure industry from 2010 to 2015, in order to illustrate the possibility and feasibility of the marketization of forest ecological compensation and operability. The channels for the marketization of the ecological compensation include: carbon sink trading, forest tourism, hydrological services and biodiversity, etc[5-6]. In recent years the mushrooming of the forest health-cultivation industry, which is a combination of many industries such as forestry, tourism, health cultivation, leisure, entertainment and pension, has provided new channels for the marketization of forest ecological compensation. The USA is the first country in the world that has developed forest health-cultivation industry, whose 1/8 of per capita income is used for forest health cultivation. The annual number of people in forest health cultivation reaches 2 billion[7]. The development of forest ecosystem services market has been institutionalized and has become one of the measures for ecological compensation in America, and has formed the market-oriented ecological compensation mechanism. Also, it provides China with references and inspiration for the development of forest health-cultivation industry and the establishment of a market-oriented mechanism for forest ecological compensation[8-9]. The vigorous development of the forest health-cultivation industry can not only regulate the existing ecological market and activate the ecological environment, but also increase the enthusiasm of forest workers for planting and protecting forests, thus enhancing forest coverage and promoting the sound development of forestry. 


\section{A REVIEW OF RELATED RESEARCH}

\section{A. Research on the Traditional Marketization of Ecological Compensation}

Ecological compensation or pay for ecological services refers to the deteriorating market environment caused by the failure of internalization of external environment due to long-term market failures, and the practices of enjoying free services of ecology system characterized by public products. The internalization of external environment can be achieved by creating markets and quasi-markets. The establishment of a market-oriented and diversified ecological compensation mechanism has attracted widespread attention of scholars at home and abroad. Wunder (2005)proposed that as long as the following conditions are met: (1) voluntary transaction, (2 ) clear ecological services, (3) purchase from eco-services buyers, (4) at least one eco-service provider, (5) the eco-service provider can guarantee the terms of eco-service, the payment of eco- services can be realized through marketization[10]. Although the marketization model proposed by Wunder was questioned at that time because many conditions could not be met, especially the condition that a transaction must be concluded be voluntary buyers, it has broadened the concept of ecology compensation.

Based on China's national conditions, domestic scholars have explored the marketization of eco-compensation models mainly from two aspects of mechanism and ways of the marketization of eco-conpensation. Li Wenhua and others made references to the practice of forest ecological benefit compensation in developed countries, and proposed suggestions on how to use the economic leverage to solve the problem of externalization and fairness of forest ecological benefits. This is an urgent problem to be solved in Chain's forest ecological benefit compensation. It is also pointed out that the marketization of forest ecology is an inevitable requirement for the development of a market economy and that diversified financing channels should be developed. In the investment and financing research for forest ecological compensation, PanHua, Xu Xing (2016) pointed out that the financing dilemma in ecological compensation can be overcome by attracting social capital in the forest ecological compensation[11]. But the conflict between public welfare of ecological compensation and the pursuit of profit of social capitals needs to be solved. By combining domestic and foreign research literature, Pan Hua and others pointed out that the packaging of ecological compensation projects with operational projects and the restructuring of the industrial chain can solve the contradiction[12]. In the marketization process of ecological compensation, scholars represented by Li Yan pointed out that forest ecological compensation mainly includes forest eco-tourism, forest carbon sinks, forest certification and forest hydrological services[6].But Chen Yanyu (2018) pointed out that China's current forest ecological compensation marketization is still in its infancy, and that there exist problems such as the ambiguity of the market body in the ecological zone, the single mode of compensation and the imperfection of the existing market-based ecological compensation efficiency system. It is still necessary to explore diversified, market-based compensation methods and establish a sound market-based ecological compensation efficiency system[13].

\section{B. Research on the Forest Health-Cultivation Industry}

Forest health-cultivation, a new term with Chinese characteristics, is still in its infant stage of development in China. Its history can be traced to the 20th century when Germany created the forest baths that rose in Japan. Currently there is no clear definition of the concept of the forest health-cultivation industry in China. Wu Houjian (2018) summarized and analyzed the definitions of forest health-cultivation from other scholars, and defined its concept in both broad and narrow senses. In a narrow sense, forest health-cultivation refers to the organic combination of high-quality forest resources with traditional medicine such as modern medicine and traditional Chinese medicine to carry out a series of activities which are beneficial to human physical and mental health, such as recuperation, health protection, rehabilitation, tourism and leisure; forest health-cultivation, in a broad sense, includes all activities that rely on forests and their environment to benefit human health [14]. Therefore, forest health-cultivation industry is mainly based on forest, and it is a series of activities and industries conducted by means of "cultivation" and for the purpose of "health".

As an emerging industry, forest health-cultivation industry explores the new forms of the forest resource sutilization, and promotes the transformation and upgrading of modern forestry[15]. $\mathrm{Xu}$ Gaofu and others proposed that forest health-cultivation industry based on the versatility of forest ecology system is an activity to give full play to the service function of forest ecological system, and also a bridge or link to related industries. The forest management unit should adopt "forest health-cultivation plus"to build its comprehensive integration of business model with related industries [16] . On the other hand, Wu Houjian[14] and Sun Baopu[17] expounded the characteristics of diversified types of forest health-cultivation products, its huge market demands and clear industry bodies. Japanese scholar Yasuo Ohe pointed out that the combination of forest health cultivation with countryside traveling internalizes the multifunction of the forest and can gain profit and provide employment opportunities.

Compared with the existing channels for forest ecological compensation marketization, forest health-cultivation industry firstly attracts a large number of social capitals into the forestry industry, providing funds for the marketization of ecological compensation. Secondly, the diversified business model of "forest health cultivation plus" provides more possibilities for the market-oriented forest ecological compensation. Thirdly, the forest health-cultivation industry, with its clear target receivers, adheres to the principle of "whoever benefits pays", effectively solving the problem of free rides. Lastly, in addition to cash compensation, the compensation method of the forest health-cultivation industry also includes compensation for intangible capital such as technology. This practice makes up for the defection of the simplification of ecological compensation method[18]. 


\section{A NEW MARKET-BASED GREY FORECASTING METHOD FOR FOREST ECOLOGICAL COMPENSATION}

Taking Latin America as an example, Grieg-Gran(2005) pointed out that insufficient willingness of environmental services for payment is the major obstacle to take more measures for the marketization of forest environmental services[19]. Based on this view, this article analyzes the willingness of Chinese citizens to pay for ecology. In recent years, along with the economic development, leisure tourism is gradually becoming the norm of people's life. Among them, ecological tourism, especially forest ecotourism is becoming more and more popular. In 2017, the structure ratio of primary, secondly and tertiary industries in China's forestry is 33:47:20, compared with $34: 53: 13$ in 2013. The proportion of forest services, mainly forest tourism and leisure tourism, has increased by $53.85 \%$. The number of visitors in forest tourism and leisure tourism has reached 3.102 billion, accounting for $67.76 \%$ of the total visitors of 4.578 billion in 2017 , generating tourism revenue of 1304.4 billion yuan, directly driving the output value of other industries to 1105.05 billion yuan. The data shows that people's demand for such luxuries as forest ecology is increasing.

Based on the original data (as shown in table 1) of tourists in 2010-2015 forest tourism and leisure tourism industry, this article forecasts the demand for forest ecotourism in the next eight years, analyzes the national demands for forest ecological products and further judges the degree of the willingness to pay for the economic value of the forest ecological benefits by applying the improved GM $(1,1)$ model.

\section{A. Introduction to Improved GM $(1,1)$ Model}

The grey system theory, proposed by Chinese Professor Deng Jvlong in 1982, is mainly used to study uncertain issues such as lack of sample data and lack of information[20]. GM $(1,1)$ is the core content of the grey system theory. In the grey prediction theory, abstract concepts of system information are quantified and modeled through some numeric data and the model is finally optimized to predict some unknown data. Compared with the traditional $\operatorname{GM}(1,1)$ model, the improved $\operatorname{GM}(1,1)$ model improve the calculation method of the background value of $\mathrm{Z}$, which makes the prediction result more accurate. Therefore, this study uses the improved GM $(1,1)$ grey model to analyze and predict the number of visitors in forestry tourism in China in the next eight years.

\section{B. Demand Analysis of Forest Ecological Products in the} Next Eight Years

Table 1. National Forestry Tourists, 2010-2015 Unit: 100 million person-times

\begin{tabular}{|c|c|c|c|c|c|c|}
\hline time & 2010 & 2011 & 2012 & 2013 & 2014 & 2015 \\
\hline number & 10.32 & 11.236 & 14.816 & 16.065 & 19.827 & 23.120 \\
of & 04 & 6 & 9 & 3 & 3 & 9 \\
tourists & & & & & & \\
\hline
\end{tabular}

Sorted from: forest statistical yearbook

According to Table 1, the data analysis process is as follows:

(1) The original data sequence of forest tourism visitors from 2010 to 2015 is

$$
X^{(0)}=\left\{x^{(0)}(1), x^{(0)}(2), x^{(0)}(3), x^{(0)}(4), x^{(0)}(5), x^{(0)}(6)\right\}
$$

The original data $x^{(0)}$ is tested by level ratio, that is

$$
\lambda^{(0)}(k)=\frac{x^{(0)}(k-1)}{x^{(0)}(k)},(k=2,3,4,5,6)
$$

If

$$
\lambda^{(0)}(k) \in\left[e^{\frac{-2}{n-1}}, e^{\frac{2}{n-1}}\right],
$$

the range ratio test passes. The range ratio of the original data $X^{(0)}$ are all in $[0.6703,1.4918]$.Then it is judged that the original data can build a GM(1,1) model.

(2) The AGO sequence is generated by first-order accumulation of the original data:

$$
\begin{gathered}
X^{(1)}=\left\{x^{(1)}(1), x^{(1)}(2), x^{(1)}(3), x^{(1)}(4), x^{(1)}(5), x^{(1)}(6)\right\} \\
x^{(1)}(k)=\sum_{i=1}^{k} x^{(1)}(i), k=2,3, \cdots, 6
\end{gathered}
$$

(3) Construct the differential equation for $X^{(1)}$. With $t=(1,2,3,4,5,6)$ as the independent variable, $x^{(1)}$ as the dependent variable, the exponential curve is fitted by the least square method

$$
x^{(1)}(t)=A e^{B t}+C
$$

and get $x^{(1)}(t)=63.59623 e^{-0.1695002 t}-53.27583$

Therefore, background value sequence is

$$
z^{(1)}=\int_{k-1}^{k}\left(63.59623 e^{-0.1695002 t}-53.27583\right) d t
$$

(4) Using $z^{(1)}(k), x^{(0)}$ establish a grey differential equation of

$$
x^{(0)}(k)+a Z^{(1)}=b, k=2,3,4,5,6
$$

and calculate by using the least multiplication

$$
u=\left(\begin{array}{l}
a \\
b
\end{array}\right)=\left(B^{T} B\right)^{-1} B^{T} Y
$$

among them,

$$
\begin{aligned}
Y & =\left(x^{(0)}(1), x^{(0)}(2), x^{(0)}(3), x^{(0)}(4), x^{(0)}(5), x^{(0)}(6)\right)^{T} \\
B & =\left(\begin{array}{cccc}
-z^{(1)}(2)-z^{(1)}(3) & -z^{(1)}(4)-z^{(1)}(5)-z^{(1)}(6) \\
1 & 1 & 1 & 1
\end{array}\right)^{T} \\
u & =\left(\begin{array}{l}
a \\
b
\end{array}\right)=\left(\begin{array}{l}
-0.1695002 \\
9.0302636
\end{array}\right)
\end{aligned}
$$

(5) Using the parameters $a$ and $b$ to establish the whitening equation of the $\operatorname{GM}(1,1)$ model

$$
\frac{d x^{(1)}(k)}{d k}+a x^{(1)}(k)=b
$$

and its corresponding time response function is

$$
x^{(1)}(k+1)=\left(x^{(0)}(1)-\frac{b}{a}\right) e^{-a k}+\frac{b}{a}
$$

and get $\tilde{\sim}^{(1)}(k+1)=63.59623 e^{-0.1695002 k}-53.27583$

then the prediction model of $x^{(0)}(k)$ is 


$$
\tilde{x}^{(0)}(k)=\tilde{x}^{(1)}(k)-\tilde{x}^{(1)}(k-1)
$$

and get $\tilde{x}^{(0)}(k)=63.59623\left(e^{-0.1695002 k}-e^{-0.1695002(k-1)}\right)$.

$k=2,3 \ldots n$. According to the prediction model (8), the calculated forest value of the number of visitors in eco-tourism from2010-2015 is shown in Table 2.

Table 2. 2010-2015actual value of eco-tourism and the predicted number of people from 2010 to 2015

unit:100million person-times

\begin{tabular}{|l|c|c|c|c|c|c|}
\hline time & 2010 & 2011 & 2012 & 2013 & 2014 & 2015 \\
\hline actual & 10.320 & 11.236 & 14.816 & 16.065 & 19.827 & 23.120 \\
data & 4 & 6 & 9 & 3 & 3 & 9 \\
\hline predic & 10.320 & 11.767 & 13.951 & 16.539 & 19.608 & 23.246 \\
t data & 4 & 6 & 0 & 5 & 3 & 5 \\
\hline
\end{tabular}

(6) Model test. For the validity of the established GM $(1,1)$ model, generally refer to the following accuracy test table.

Table 3. Reference of accuracy inspection grades

\begin{tabular}{|l|c|c|c|c|}
\hline & $\begin{array}{l}\text { Relative } \\
\text { error }\end{array}$ & $\begin{array}{l}\text { Correla } \\
\text { tion }\end{array}$ & $\begin{array}{l}\text { mean variance } \\
\text { ratio C }\end{array}$ & $\begin{array}{l}\text { small error } \\
\text { probability P }\end{array}$ \\
\hline $\begin{array}{l}\text { First } \\
\text { level }\end{array}$ & 0.01 & 0.90 & 0.35 & 0.95 \\
\hline $\begin{array}{l}\text { scondar } \\
\text { y }\end{array}$ & 0.05 & 0.80 & 0.5 & 0.80 \\
\hline $\begin{array}{l}\text { Third } \\
\text { grade }\end{array}$ & 0.10 & 0.70 & 0.65 & 0.70 \\
\hline $\begin{array}{l}\text { Fourth } \\
\text { grade }\end{array}$ & 0.20 & 0.60 & 0.80 & 0.60 \\
\hline
\end{tabular}

The smaller the relative error, the better; the greater the correlation, the better; the smaller the mean square error ratio, the better, and the greater the small error probability, the better.

Define the sequence $X^{(0)}$ to be absolutely related to $\hat{X}$, absolute correlation

$$
\begin{aligned}
& \rho=\frac{1+|s|+|\hat{s}|}{1+|s|+|\hat{s}|+|s-\hat{s}|} \\
&|s|=\left|\sum_{k=2}^{n-1} x^{(0)}(k)+\frac{1}{2} x^{(0)}(n)\right| \\
&|\hat{s}|=\left|\sum_{k=2}^{n-1} \hat{x}^{(0)}(k)+\frac{1}{2} \hat{x}^{(0)}(n)\right| \\
&|s-\hat{s}|=\left|\sum_{k=2}^{n-1}\left(x^{(0)}(k)-\hat{x}^{(0)}(k)\right)+\frac{1}{2}\left(x^{(0)}(n)-\hat{x}^{(0)}(n)\right)\right|
\end{aligned}
$$

If mean variance ratio $C=\frac{S_{2}}{S_{1}}$, let $X^{(0)}$ be the original sequence, $\hat{X}^{(0)}$ is the corresponding simulation sequence and $\varepsilon^{(0)}$ is residual sequence.

$$
\begin{gathered}
\bar{x}=\frac{1}{n} \sum_{k=1}^{n} x^{(0)}(k) \\
\tilde{x}^{(0)}(k)=\tilde{x}^{(1)}(k)-\tilde{x}^{(1)}(k-1) \\
S_{1}^{2}=\frac{1}{n} \sum_{k=1}^{n}\left(x^{(0)}(k)-\bar{x}\right)^{2}
\end{gathered}
$$

Mean and variance of $\varepsilon^{(0)}$ respectively

$$
\begin{gathered}
\bar{\varepsilon}=\frac{1}{n} \sum_{k=1}^{n} \varepsilon^{(0)}(k) \\
S_{2}^{2}=\frac{1}{n} \sum_{k=1}^{n}(\varepsilon(k)-\bar{\varepsilon})^{2}
\end{gathered}
$$

are the mean and variance of the residuals.

Small error probability

$$
p=P\left(|\varepsilon(k)-\bar{\varepsilon}|<0.6745 S_{1}\right)
$$

Using R software and programming, the validity of the GM $(1,1)$ model constructed from the original data series of forest tourism trips from 2010 to 2015 was tested, and the results are:

Table 4. Model evaluation table

\begin{tabular}{|l|l|l|c|}
\hline $\begin{array}{l}\text { Relative } \\
\text { error }\end{array}$ & $\begin{array}{l}\text { Correlatio } \\
\mathrm{n} \rho\end{array}$ & $\begin{array}{l}\text { mean } \\
\text { variance } \\
\text { ratio C }\end{array}$ & $\begin{array}{l}\text { small error } \\
\text { probability P }\end{array}$ \\
\hline 0.01004985 & 0.998890 & 0.04548819 & 1 \\
\hline
\end{tabular}

According to Table 4, the average relative error of the prediction model is $1.005 \%$, less than $5 \%$. The mean square deviation ratio $\mathrm{C}$ is 0.0455 , less than 0.5 ; The small error probability is 1 , greater than 0.8 . Therefore, it can be judged that this model is a first level model.

Since $-a=0.1695002<0.3$, so

$$
\begin{aligned}
& \tilde{x}^{(0)}(k)=\tilde{x}^{(1)}(k)-\tilde{x}^{(1)}(k-1) \\
& =63.59623\left(e^{-0.1695002 k}-e^{-0.1695002(k-1)}\right)
\end{aligned}
$$

$k=2,3 \ldots n$, can be used for medium and long-term prediction. Therefore, the forecasting results for 2016-2023 are shown in Table 5.

Table 5. The predicted value of visits in forestry tourism and leisure industryfrom 2016-2023

\begin{tabular}{|l|l|l|l|l|}
\hline time & 2016 & 2017 & 2018 & 2019 \\
\hline $\begin{array}{l}\text { predict } \\
\text { value }\end{array}$ & 27.41529 & 32.47923 & 38.47856 & 45.58603 \\
\hline time & 2020 & 2021 & 2022 & 2023 \\
\hline $\begin{array}{l}\text { predict } \\
\text { value }\end{array}$ & 54.00634 & 63.98199 & 75.80027 & 89.80153 \\
\hline
\end{tabular}

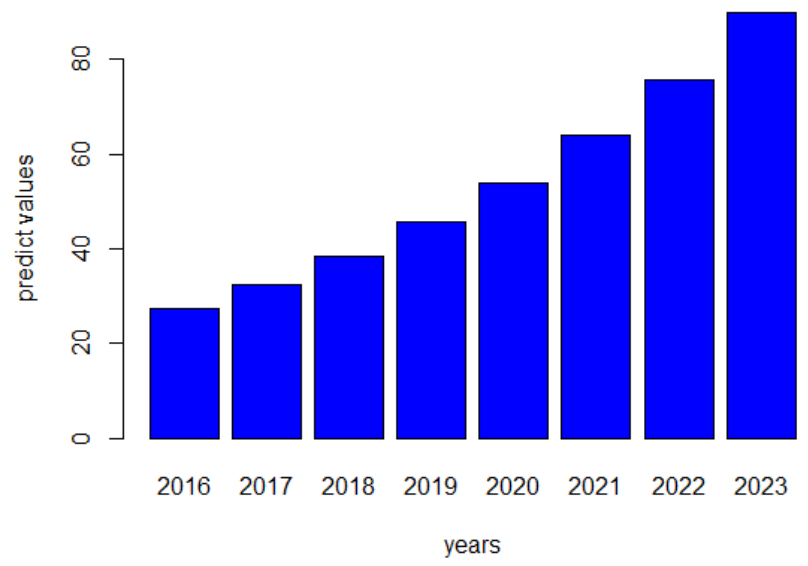

Fig. 1 2016-2023 forest tourism and leisure industry visits forecast trend analysis chart 
It can be seen from Table 6 and Figure 1 that the number of people participating in the forestry tourism and leisure industry in the next eight years has risen obviously. By 2023, it will reach 8.98 billion person-times, which is 6.2 times as much as China s predicted population of 1.436 billion in 2023 . This also shows that the people's demand of luxury goods such as forest ecology is gradually increasing. It also further illustrates that people are willing to pay for the economic value of the forest ecological benefits, the increase in national demand for forest ecological products will promote the development of the forest health industry, thereby promoting the diversification, incrementalization and marketization of forest ecological compensation, thereby improving the forest ecological compensation market system and improving the formation of the value of forest ecological products. It further improved the ecological compensation mechanism. This will in turn promote the development of the forest health industry. In addition to the increasing demand, the problem of old age caused by the aging of the population, national health problems caused by "sub-health", and high incidence rates of chronic deceases have also accelerated the development of the forest health-cultivation industry.

In short, the rapid growth for ecological demand and great importance attached to the forest health-cultivation industry by the government, have created a market for the forest ecological benefits, cultivated a market environment for ecologicalcompensation, and provided opportunities for the marketization of forest compensation.

\section{DISCUSSION}

By using the $G(1,1)$ model prediction method, it shows: The forest health industry has effectively promoted the development of rural tourism. It is based on the multi-functionality of forest ecology and seeks a balance and growth point between the three major benefits of forest ecology, economy and society, it provides a channel for the transition from "blood transfusion" compensation to "hematopoiesis" and from passive to active forest ecological compensation, which fully embodies the principle of "who benefits, who pays", intensified the marketization of forest ecological compensation, and provided continuous driving force and impetus to improve the marketization mechanism of forest ecological compensation, which is specifically shown as follows:

(1) The emergence of the forest health industry has broadened the scope of forest ecological compensation and improved the ecological compensation mechanism for public welfare forests. The forest health industry mainly relies on high-quality forests such as forest parks, wetland parks, national parks and state-owned forest farms to carry out various leisure and health activities, contains local-level public welfare forests and other high-quality forest lands that cannot be compensated for. It makes up for the centralized and single compensation problem of the forest ecological compensation fund only compensating for national public welfare forests, thereby improving the ecological compensation mechanism for public welfare forests.

(2) The development of the forest health industry provides employment opportunities for the society, promotes targeted poverty alleviation, improves the situation of low compensation, and has a certain effect on poverty alleviation and poverty alleviation. The development of the forest health industry can promote the development of local tertiary industries such as catering and transportation, and provide more sources of part-time income for local forest farmers. In addition, the development of the forest health industry requires specialized forest function explainers, forest therapists and other professional health workers. This can provide more employment opportunities for local forest farms and transform local employable poor households into forest protection personnel, which not only achieves targeted poverty alleviation and poverty alleviation, but also improves forest farmers' enthusiasm for forest protection. Although the government's blood transfusion-style forest compensation can also improve the living standards and quality of life of forest farmers to a certain extent, However, relying on government financial subsidies to alleviate poverty is not a long-term solution. This kind of hematopoietic forest compensation for industrial development can fundamentally solve the problem of poverty in forest areas.

(3) The advancement of the forest health industry has formed a value compensation pattern of "who benefits, who pays". Although the compensation method based on government purchases of services has improved the efficiency of ecological compensation, it has lost the compensation order and fairness, and cannot form a compensation pattern of "who benefits, who pays". Forest health care can be divided into two categories: public health care and high-end health care according to the different beneficiaries. Public health care mainly serves ordinary people. For example, the construction of forest health trails with the nature of public goods in the National Forest Park, but the government still uses the way of purchasing forest ecological services; while high-end health care is targeted at specific groups, such as the construction of forest rehabilitation Centers and forest hospitals have the characteristics of typical revenue services and adopt the beneficiary's payment method. To a certain extent, the advancement of the forest health industry has formed an ecological value compensation pattern of "who benefits and pays".

(4) The popularization of the forest health industry can raise funds through multiple channels and increase the marketization of ecological compensation. China's forest ecological compensation fund mainly comes from financial vertical transfer payments, and the source of funds is single. The forest health industry mostly uses the PPP method for financing, attracting a large amount of social capital to invest in forest ecological construction and protection, expanding the source of forest ecological compensation funds, and extracting part of the forest ecological product prices after marketization for forest ecological compensation. While alleviating the pressure on national fiscal expenditures, it has also increased the marketization of ecological compensation and accelerated the formation of a market-based compensation mechanism. 


\section{CONCLUSION}

Forestry is both a public welfare undertaking that improves ecology and a basic industry that develops the economy and improves people's livelihood. The marketization of forest ecological products is an inevitable trend under the market economy system. Forest health-cultivation industry is a combination of health industry and forestry. It largely converts the forest ecological values to economic values, and complement the ideology that"Lucid waters and lush mountains are invaluable assets." The development of the forest health industry can increase the income of forest farmers from part-time work, increase the progress of the marketization of forest ecological compensation, improve the market mechanism and other benefits, and mobilize the enthusiasm of forest farmers, governments, communities, etc. It not only solves the ecological problem of "greening up", but also pays attention to the livelihood issues of forest workers "to become better-off". People's yearly increasing demand for ecological products has added to people's willingness to pay for ecological products, and people's awareness of compensation has been enhanced day by day. The G(1,1) model provides a new method for exploring the development of the forest health industry, urging the government to coordinate, and forming a diversified and market-oriented mechanism for ecological compensation.

\section{ACKNOWLEDGEMENTS}

This work is supported by Reseach on the Development Path of Guangxi Cultural and Creative Agriculture(Project Number:G2018001) and The Basic Research Ability Improvement Projict for Young and Middle-aged Teachers in Guangxi Universities(Project Number:2020KY14013)

\section{REFERENCES}

[1] X.Y. Cao, Y.C.Liu."Analysis on the Marketization Compensation Approaches of Forest Ecological Benefits in China "Forestry Economic Issues, 2011, 31(1):16-19

[2] Q.J. Wang, S.Q. Cai."Legal Research on Ecological Compensation Mechanism" Social Sciences in Nanjing, 2006, (07): 73-80.

[3] G.D. Xie, S.Y. Cao."The Status and Trend of the Development of Ecological Compensation Mechanism "Enterprise Economy,2016,(04):32-35.

[4] S.Engel, S.Pagiola, etc, "Designing payments for environmental services in theory and practice: An overview of the issues" Ecological Economics, 2008, 65(4):663-674.

[5] X.Y. Cao,Y.C. Liu."Analysis on Marketization Compensation Approaches of Forest Ecological Benefits in China" Forestry Economic Issues, 2011, 31 (1): 16-19.

[6] Y.Li, "Research on Marketization of Forest Ecological Benefit Compensation" Science and Technology Outlook, 2016, 26 (11), 72-72.

[7] S.J.Wang,Y.Jiao,"Foreign Forest Ecological Benefits Compensation System and Its Reference"Eco-economics, 2011, (01): 69-73.

[8] S.l.Deng,"Theoretical Research and Practice of Forest Health"World Forestry Research, 2016,29 (06): 1-6.
[9] G.V.Hecken, J. Bastiaensen,"Payments for ecosystem services: justified or not? "A political view" Environmental Science and Policy, 13 (2010), pp. 785-792

[10] G.-G.M,etc, "How can market mechanisms for forest environmental services help the poor? "Preliminary lessons from Latin America. World Development, 2005, 33(9):1511-1527.

[11] W.J. Li,F,etc, "Research Status and Prospect of Forest Ecological Benefit Compensation"Journal of Natural Resources, 2006 (05): 677-688.

[12] H.Pan,X.Xu, "Review of Research on Market Mechanism of Investment and Financing for Ecological Compensation "Journal of Kunming University of Science and Technology (Social Science Edition), 2016,16 (01): 59-64.

[13] Y.Y. Chen,"Marketization Path and Countermeasures of Ecological Compensation Mechanism in the New Era "Journal of Changsha University of Science and Technology (Social Science Edition), 2018,33 (03): 110-115.

[14]H.J.Wu, X.Q. Dan,etc,"Forest well-being: concept, product type and development path"Chinese Journal of Ecology, 2018,37 (07): 2159 -2169.

[15] S.Q.Zhang, “Thinking about Developing Forest Recreation Industry and Promoting Modern Forestry Transformation and Upgrade "Forestry Economy, 2018,40 (08): 42-46.

[16] G.F. Xu,etc."What is forest recreation?—-Thinking based on the integration of forest multifunctionality and related business formats"Forestry Economy, 2018,40 (08): $58-60+103$.

[17] B.P.Sun,"“'Forest well-being” is a new format and model of China's big health industry" Commercial Culture, 2015 (22): 82-83.

[18] Y.Oe,etc."Evaluating the relaxation effects of emerging forest-therapy tourism: A multidisciplinary approach" Tourism Management, 2017, 62:322-334.

[19] G.-G.M,etc, "How can market mechanisms for forest environmental services help the poor? Preliminary lessons from Latin America"World Development, 2005, 33(9):1511-1527.

[20] S. F. Liu,J.1. Deng,"Application scope of GM $(1,1)$ model” Systems Engineering Theory \& Practice, 2000, (05): 121-124.

[21] J. Li, “China's New Industry of Forest Rehabilitation and Health"China Forestry Industry, 2017 (3): 21-22.

[22] G.D.Xie,S.Y.Cao,et al. "The status and trends of ecological compensation in China"Journal of Resources and Ecology, 2015, 6 (6): 355-362. 
BIOGRAPHY

Xingang Wang was born in Jixi,Heilongjiang,China, Associate Professor, School of Business, Yulin Normal University, $\mathrm{PhD}$ of Management, mainly studies Agriculture and Forestry Economic actuarial/management Management/data platform
Creative Commons Attribution License 4.0 (Attribution 4.0 International, CC BY 4.0)

This article is published under the terms of the Creative Commons Attribution License 4.0

https://creativecommons.org/licenses/by/4.0/deed.en_US

Shide Ou was born in 1964 in Yulin, Guangxi, China. Professor, $\mathrm{PhD}$ of Statistics, Schoolof Mathematics and Statistics, Yulin Normal University, mainly studies statistics and mathematics.

ShangzhiYue was born in Harbin,Heilongjiang,China, Professor, $\mathrm{PhD}$ of Management, postdoctoral, doctoral supervisor, postdoctoral contact, provincial and ministerial key accounting discipline leader, person in charge, agricultural and forestry economic management doctoral discipline accounting leader. The author is the corresponding author. 